\title{
Organic matter from redoximorphic soils accelerates and sustains microbial Fe(III) reduction
}

Andreas Fritzsche ${ }^{a, 1, *}$, Julian Bosch ${ }^{b, 1}$, Michael Sander ${ }^{c}$, Christian Schröder ${ }^{d}$, James M. Byrne ${ }^{e, 2}$, Thomas Ritschel $^{a}$, Prachi Joshi ${ }^{e}$, Markus Maisch ${ }^{e}$, Rainer U. Meckenstock ${ }^{b, 3}$, Andreas Kappler $^{e}$, Kai U. Totsche ${ }^{a}$

${ }^{a}$ Institute of Geosciences, Friedrich-Schiller-University Jena, Burgweg 11, D-07749 Jena, Germany (thomas.ritschel@uni-jena.de, kai.totsche@uni-jena.de)

${ }^{\mathrm{b}}$ Institute of Groundwater Ecology, Helmholtz Center Munich - German Research Center for Environmental Health, D-85764 Neuherberg, Germany

${ }^{c}$ Department of Environmental Systems Science, Institute of Biogeochemistry and Pollutant Dynamics, Swiss Federal Institute of Technology (ETH) Zurich, CH-8092 Zurich, Switzerland (michael.sander@env.ethz.ch)

d Biological and Environmental Sciences, Faculty of Natural Sciences, University of Stirling, Stirling FK9 4LA, UK (christian.schroeder@stir.ac.uk)

${ }^{\mathrm{e}}$ Geomicrobiology, Center for Applied Geosciences, University of Tübingen, D-72076 Tübingen, Germany (prachi.joshi@uni-tuebingen.de; markus.maisch@uni-tuebingen.de; andreas.kappler@uni-tuebingen.de)

${ }^{1}$ present: Intrapore GmbH, D-45327 Essen, Germany (julian.bosch@intrapore.com)

${ }^{2}$ present: School of Earth Sciences, Bristol BS8 1RJ, UK (james.byrne@bristol.ac.uk)

${ }^{3}$ present: Environmental Microbiology and Biotechnology, University of Duisburg-Essen, D-45141 Essen, Germany (rainer.meckenstock@uni-due.de)

* Corresponding author. Tel.: +49 3641948 715; fax: +49 3641948 742; a.fritzsche@uni-jena.de

This Supporting Information contains 18 pages (incl. cover sheet and bibliography) with 8 figures, 6 tables and one text section with details on i) the used topsoil material, ii) the design of the soil column experiment and the microbial reduction experiments, iii) the soil effluent OM (efOM; ${ }^{13} \mathrm{C}-\mathrm{NMR}$ spectra, FTIR spectra, XRD patterns), iv) the properties of ancillary OM specimens for comparison purposes, v) the measured Mössbauer spectra and corresponding fits, and vi) the aggregate properties of OM-free ferrihydrite used for the microbial reduction experiments. 
Table S1. Texture, $\mathrm{pH}$, effective cation exchange capacity $\left(\mathrm{CEC}_{\text {eff }}\right)$, contents of organic carbon (OC), inorganic carbon (IC), and dithionite-extractable Fe (Fe $\left.\mathrm{D}_{\mathrm{D}}\right)$ in a humus-rich top horizon ( $\mathrm{Ah}$ ) of a floodplain soil (periodically flooded gleyic Fluvisol) and its volumetric water content and corresponding liquid-to-solid ratios in the soil columns. \pm : $\mathrm{min} /$ max deviation from arithmetic mean of two independent replicates except for *, where \pm denotes the standard deviation ( $\mathrm{n}=3$ ). d.1.: detection limit

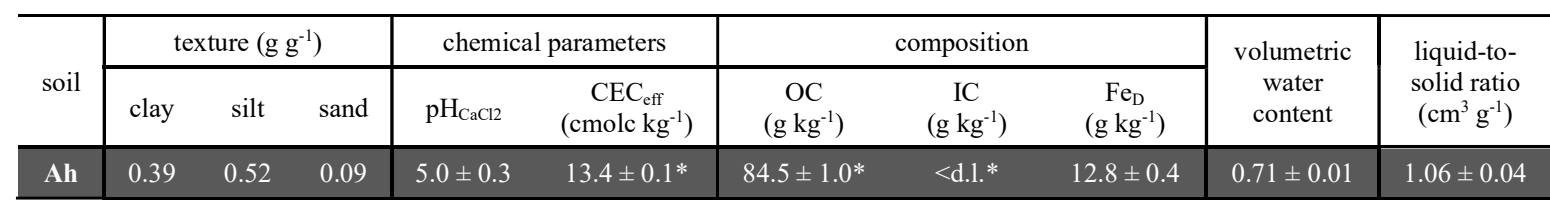

Texture was determined in $<2 \mathrm{~mm}$ sieved soil, which was prior oxidized with $\mathrm{H}_{2} \mathrm{O}_{2}(30 \%)$. The soil was dispersed with $0.0125 \mathrm{M} \mathrm{Na}_{4} \mathrm{P}_{2} \mathrm{O}_{7}$ and shaken for $16 \mathrm{~h}$, followed by wet sieving for quantification of sand ( $>63 \mu \mathrm{m})$. Silt ( $>2 \mu \mathrm{m} ; \leq 63 \mu \mathrm{m})$ was determined using X-ray attenuation (Sedigraph 5100, Micromeritics). All soil particles, which were not recovered as sand or silt, were considered as clay. Soil pH was determined potentiometrically (Sentix $41+\mathrm{pH} 197 \mathrm{i}$; WTW) in $0.01 \mathrm{M} \mathrm{CaCl}_{2}$ at a liquid-to-solid ratio of $2.5 \mathrm{ml} \mathrm{g}^{-1}$. Effective cation exchange capacity ( CEC $_{\text {eff }}$ ) was determined according to the German Institute for Standardization ${ }^{1}$. Organic carbon (OC) was analyzed by combustion of soil (Multi N/C 2100, Analytik Jena) after fumigation with $\mathrm{HCl}^{2}$ Inorganic carbon (IC) was calculated as difference between $\mathrm{OC}$ and the C content in soil samples that were not treated with $\mathrm{HCl}$. Dithionite-extractable Fe (FeD) was quantified according to Mehra and Jackson ${ }^{3}$. The volumetric water content was calculated from the influent volume, which was required for full water-saturation of the initially dry soil in the columns.

The high volumetric water content is related to the comparably high clay content and thus a comparably high contribution of pore space to the total soil volume. This large amount of pore space and the low bulk density of Ah $\left(0.665 \pm 0.024 \mathrm{~g} \mathrm{~cm}^{-3}\right) \mathrm{resulted}$ in a comparably high liquidto-solid ratio, which is nevertheless characteristic of such topsoils when completely water-saturated, e.g., during inundation with river water during regularly occurring flood events. ${ }^{4}$ 
Supporting Information S1. Percolation protocol

Before effluent sampling, the soil columns were percolated for $\sim 2$ pore volumes to remove unusually high concentrations of microbial biomass from the soil, ${ }^{5}$ which formed as a result of lysis of microbial cells during air-drying. ${ }^{6}$ A complete drying out of soil -as it was conducted before the experiment- is not characteristic under in situ conditions since a certain moisture level is permanently maintained in intact soils under temperate climate. ${ }^{7}$ We therefore considered this initial flush of microbial biomass-rich OM from air-dried soil as unrepresentative for OM that is available at anoxic-oxic interfaces in intact soils.

To promote the depletion of available oxygen, an initial flow interrupt $(60 \mathrm{~d})$ was conducted. As a consequence, reduction of Fe(III) and $\mathrm{SO}_{4}{ }^{2-}$ established within the soil columns due to the activity of autochthonous microbial communities and led to the reductive dissolution of pedogenic iron (oxyhydr-)oxides. Iron- and sulfate-reducing conditions were indicated by i) the presence of dissolved Fe(II) as sole iron species in the soil effluent, ii) the complete absence of effluent $\mathrm{SO}_{4}{ }^{2-}$ despite permanently present effluent $\mathrm{S}^{4}$ and iii) soil effluent redox potentials of $\sim 100 \mathrm{mV}$ (against standard hydrogen electrode; Figure S1). 


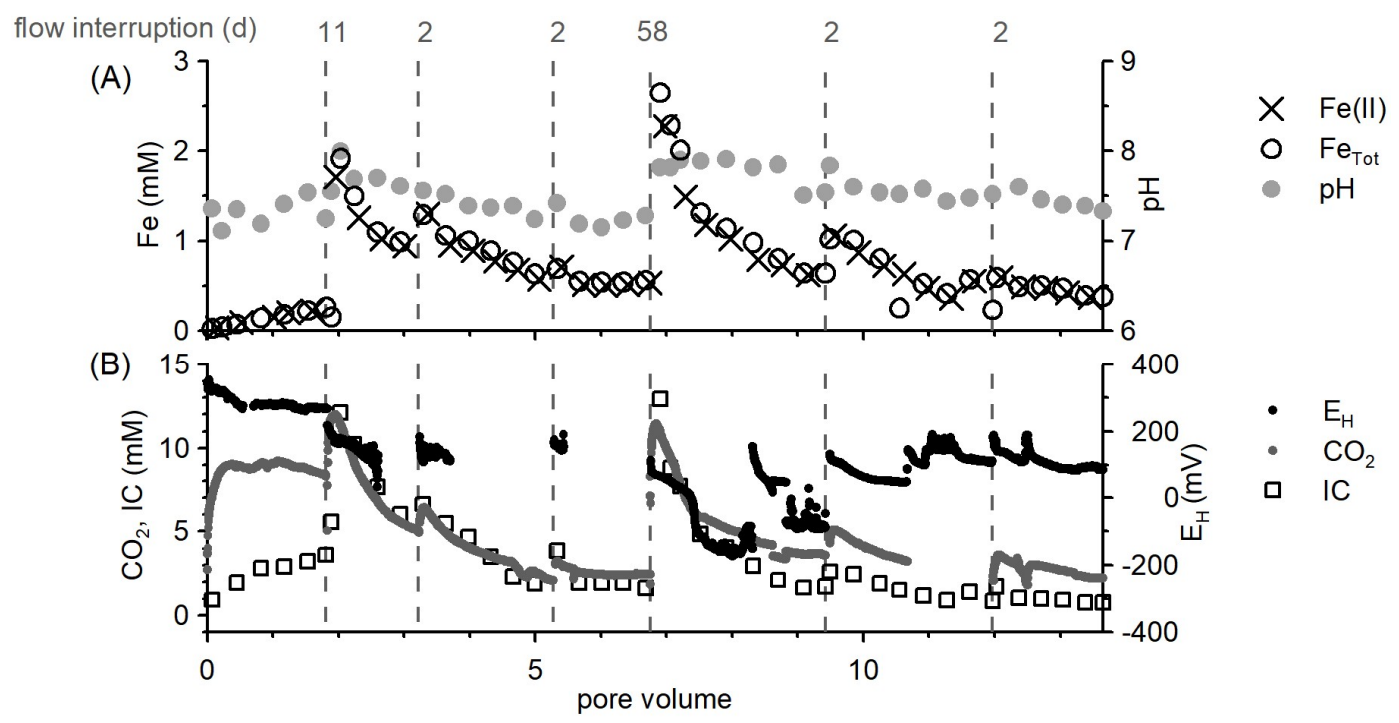

Figure S1. (A) Effluent $\mathrm{pH}$ and concentrations of $\mathrm{Fe}(\mathrm{II})$ and total $\mathrm{Fe}\left(\mathrm{Fe}_{\mathrm{Tot}}\right)$ and (B) $\mathrm{CO}_{2}$, inorganic carbon (IC) and effluent redox potentials ( $\left.\mathrm{E}_{\mathrm{H}}\right)$ in response to interrupted percolation (dashed lines, grey values: corresponding duration) during a column experiment with topsoil material of the floodplain site (Ah; Table S1). This separate column experiment was operated under identical conditions as described in the manuscript.

$\mathrm{Fe}(\mathrm{II})$ was determined by first sampling the soil column effluent in $\mathrm{HCl}$ (final concentration: $0.25 \mathrm{M}$ ) to effectively retard the oxidation of Fe(II) ${ }^{8}$ followed by photometrical analysis at $510 \mathrm{~nm}$ (Spectronic 601, Milton Roy) after complexation with 1,10-phenanthroline. ${ }^{9}$ Total Fe was determined in unfiltered effluent with ICP-OES (VistaPro, Varian). Effluent pH was analyzed potentiometrically in unfiltered samples (Sentix $41+\mathrm{pH}$ 197i, WTW). Inorganic carbon (IC) was calculated as difference between non-purgeable total C (non-acidified samples) and organic C (acidified samples) (TOC-5050A, Shimadzu). $\mathrm{CO}_{2}$ concentrations and $\mathrm{E}_{\mathrm{H}}$ were monitored online in the soil effluent by a gas sensitive $\mathrm{CO}_{2}$ electrode (Mettler Toledo) and an Ag sensor redox electrode (SenTix Ag, WTW), respectively. Both devices were mounted into separate stainless-steel flow-through cells, which were installed in the outflow path. We calculated the potential of the standard hydrogen electrode ( $\left.E_{H}\right)$ by adding $211 \mathrm{mV}$ to the recorded potentials (experiment temperature: $295 \pm 2 \mathrm{~K}$ ). ${ }^{10}$

Uniform concentrations of $\mathrm{Fe}(\mathrm{II})$ and total Fe revealed that Fe was discharged from soil solely as Fe(II). Microbial activity was indicated by formation of $\mathrm{CO}_{2}$ as well as by the accompanied presence of bicarbonate, which was detected as IC in the effluent. The release of IC from the soil matrix can be excluded due to its absence in the soil (Table S1). Effluent $E_{H}$ dropped from $450 \mathrm{mV}$ (influent) to $\sim 100 \mathrm{mV}$, which is in agreement with conditions of microbial Fe(III) reduction at circumneutral $\mathrm{pH},{ }^{11}$ which was predominant in the effluent. 

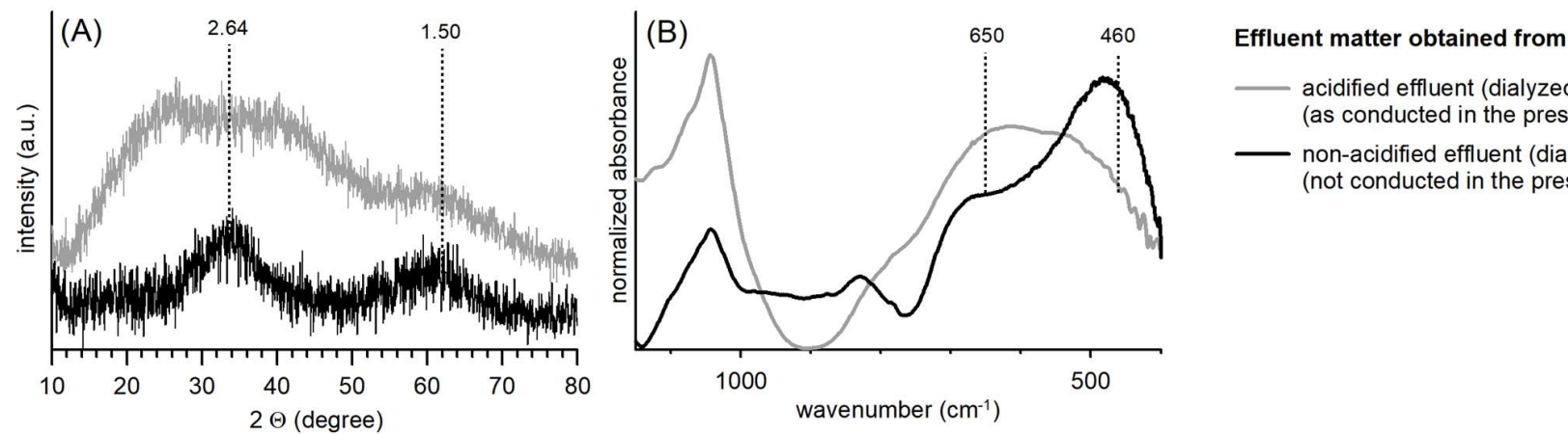

- acidified effluent (dialyzed) (as conducted in the present study)

non-acidified effluent (dialyzed) (not conducted in the present study)
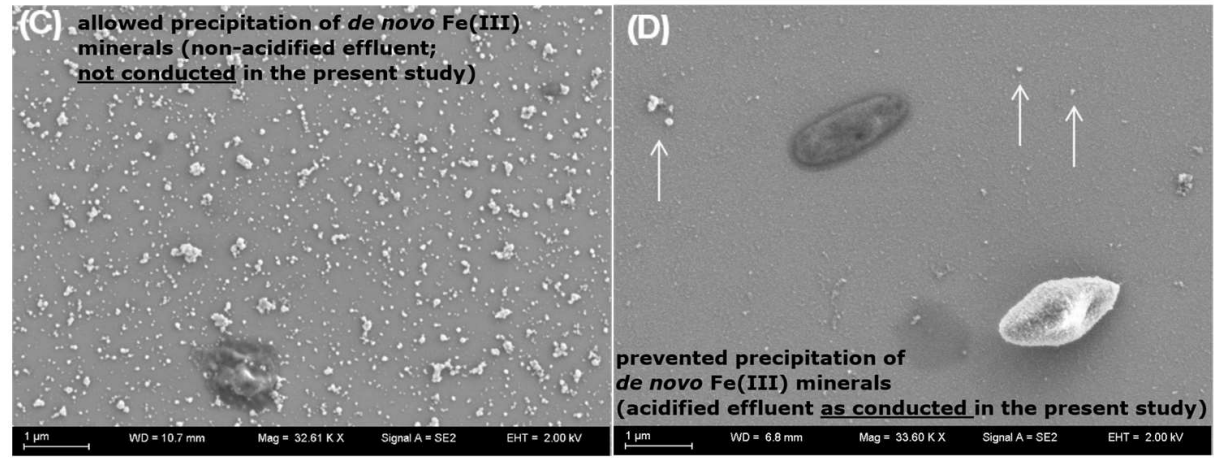

Figure S2. (A) X-ray diffraction patterns and (B) FTIR spectra of freeze-dried, dialyzed soil column effluent that either was not acidified (black) or was immediately acidified upon discharge (grey). The effluent was obtained from the same soil column filled with a humus-rich top horizon of a floodplain soil (Table S1). (C) and (D) show the corresponding secondary electron images of non-acidified and acidified soil effluent, respectively. Values in A): d-spacings. Values in B) wavenumbers of interest. Arrows in D) Spots of interest.

$\mathrm{X}$-ray diffraction patterns were obtained as described in the main text. FTIR spectra were recorded in transmission mode using a Nicolet iS10 spectrometer (Thermo Fisher Scientific). The samples $(\sim 1 \mathrm{mg})$ were mixed with $\mathrm{KBr}(\sim 250 \mathrm{mg}$; FTIR spectroscopy grade, Merck), mortared and pressed to pellets. The pellets were measured at wavenumbers from 4000 to $400 \mathrm{~cm}^{-1}$ with 16 scans per spectrum at a resolution of $4 \mathrm{~cm}^{-1}$. The spectra were baseline-corrected and normalized to maximum intensity. For scanning electron microscopy, $10 \mu 1$ of dialyzed effluent (100$500 \mathrm{Da}$, Spectra/Por Biotech CE, Spectrum Laboratories) were air-dried on a Si wafer. Analysis was conducted with an ULTRA PLUS field emission scanning electron microscope (Zeiss).

The diffraction patterns of non-acidified soil effluent exhibited broad reflections at $\sim 34{ }^{\circ} 2 \theta$ and $\sim 62{ }^{\circ} 2 \theta$ (Figure S2A), which indicated the presence of low-crystalline, ferrihydrite-rich Fe-OM coprecipitates. ${ }^{12}$ FTIR spectra confirmed the presence of ferrihydrite ${ }^{13}$ in the precipitates from non-acidified soil effluent by respective bands at $460 \mathrm{~cm}^{-1}$ and $650 \mathrm{~cm}^{-1}$ (Figure S2B). In SEM images, the Fe-OM coprecipitates were identified as colloidal aggregates (Figure S2C). ${ }^{12}$ In contrast, matter from freeze-dried effluent, which was acidified upon discharge from the soil columns, exhibited a broad reflection from $20-50{ }^{\circ} 2 \theta$ in the diffractogram (Figure S2A). This was likely caused by OM-induced X-ray fluorescence. The FTIR spectrum also lacked of distinct bands characteristic of ferrihydrite (Figure S2B). After dialysis of the acidified soil column effluents, the residual Fe fraction comprised $0.17 \pm 0.05$ of the initially discharged Fe (arithmetic mean \pm range of two independent soil column replicates). Accordingly, the molar $\mathrm{OC} / \mathrm{Fe}$ ratio increased during dialysis from $5.5 \pm 0.9$ to $12.8 \pm 1.6$. This suggests the presence of colloidal Fe-OM coprecipitates also in the dialyzed, formerly acidified soil effluent fractions. Supposedly, the removal of Fe(II) from the effluent was still incomplete, when the dialysis-induced increase in $\mathrm{pH}$ (before dialysis: $\mathrm{pH} \sim 1.0$, after dialysis: $\mathrm{pH} \sim 5.0$ ) allowed for a sufficiently fast oxidation of $\mathrm{Fe}(\mathrm{II})$ and subsequent hydrolysis of $\mathrm{Fe}(\mathrm{III})$. The relative content of $\mathrm{Fe}-\mathrm{OM}$ coprecipitates was too low for unambiguous detection with X-ray diffractometry and FTIR spectroscopy. In contrast, the SEM images confirmed the occasional presence of aggregates, which were identically shaped to the Fe-OM coprecipitates in not acidified soil effluent (highlighted in Figure S2D). 


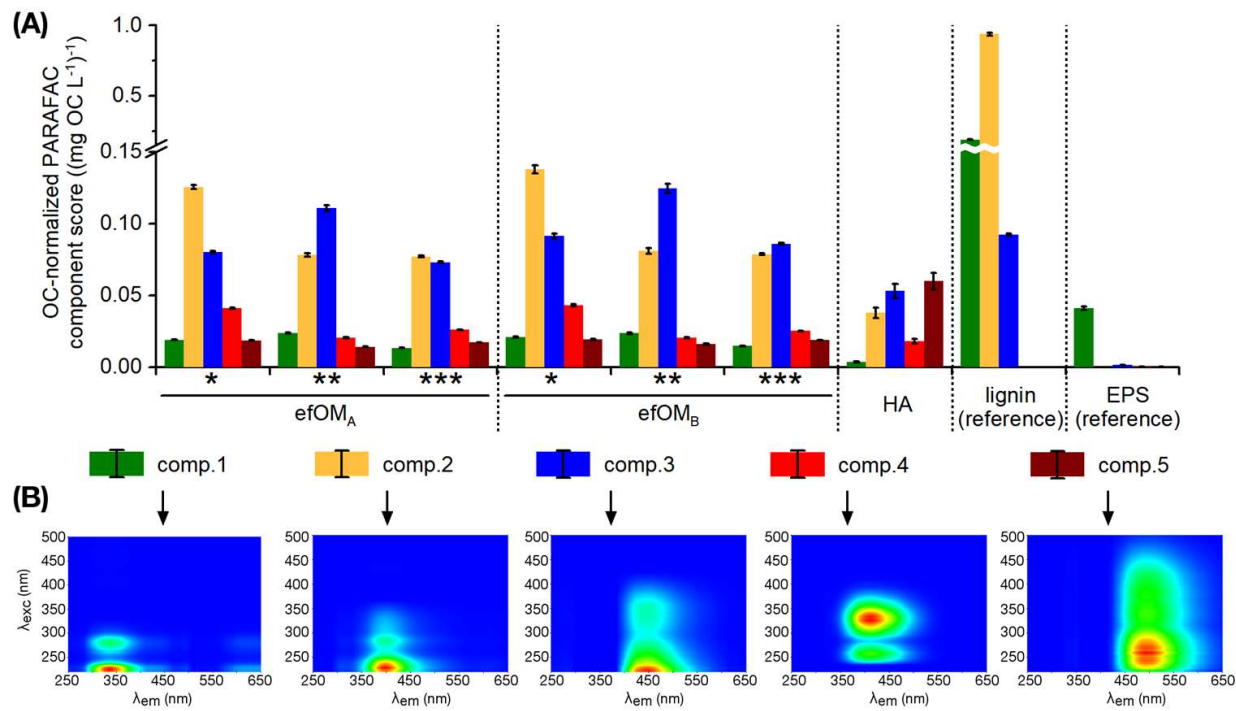

Figure S3. (A) OC-normalized scores of a 5-component parallel factor analysis (PARAFAC) to reconstruct the excitation-emission-matrices (EEM, Table S2) of organic matter (OM). efOM: soil effluent OM from an anoxic topsoil of a floodplain site (Table S1). AB: independent replicates. *: instantly acidified soil column effluent $(\mathrm{pH} \sim 1)$. ${ }^{* *}$ : dialyzed $*(\mathrm{pH} \sim 5)$. ${ }^{* *}$ : re-acidified ${ }^{* *}(\mathrm{pH} \sim 1)$. EPS: extracellular polymeric substances from Bacillus subtilis. HA: humic acid from anoxic groundwater. lignin: sulfonated lignin. pH of HA, lignin and EPS similar to ** (Table S2). Error bars: standard error. (B) EEM of the single components used in PARAFAC. Experimental details on EEM generation are given in Table S2.

Fluorescence spectroscopy can be used to directly analyze OM without any pre-treatment (except for dilution) and to assess molecular changes (in the vicinity) of fluorophores. The preparation of efOM for the microbial reduction experiments required the dialysis of the soil column effluents. To assess the impact of dialysis, we collected EEM of the soil column effluents before and after dialysis (Table S2). Since pH changes also alter the OM fluorescence, ${ }^{14,15}$ the effluents were re-acidified after dialysis to undo the dialysis-induced $\mathrm{pH}$ increase. For factorization of the EEM with PARAFAC, we chose a 5 component-model, which resembled tryptophan-like fluorescence (comp.1), polyphenol-like fluorescence (comp.2) and humic-like fluorescence (comp.3-5; Figure S3B). Commonly, two components are sufficient to represent humic-like fluorescence. ${ }^{16,17}$ In our study, instead, the factorization of treatment-induced changes (dialysis, acidification) required two components (comp.3+4) in the blue-shifted region of humic-like fluorescence to avoid systematically distributed residuals.

In efOM, the humic-like fluorescence (comp.3-5) was reproducibly dominated by the blue-shifted component (comp.3). This points to macromolecules with rather low molecular weights, ${ }^{16}$ in which the fluorophore is surrounded by a framework of decreased conjugation. This is characteristic of microbially processed OM. ${ }^{18}$ Contrary, HA from anoxic groundwater exhibited a more red-shifted fluorescence. This is a common finding and points to more conjugated macromolecules with higher molecular weights in HA. ${ }^{16}$ The EEM of efOM showed tryptophanlike fluorescence, which exclusively contributed to the fluorescence of EPS from Bacillus subtilis (comp.1). We regarded comp.1 as indicator for aromatic proteins. ${ }^{19}$ However, tryptophan-like fluorescence can be confused with fluorescence of plant-derived polyphenols. ${ }^{20}$ This was confirmed by the use of comp. 1 to reconstruct the EEM of sulfonated lignin (Figure S3A), although proteins were negligible in this OM $(\mathrm{C} / \mathrm{N}=$ 190). Thus, comp.1 may be used to a certain extent to explain a dominant fluorescence of polyphenols, hypothetically also in efOM. Tryptophanlike fluorescence nevertheless contributed to comp.1 in efOM considering its protein content (Table 1, Figure S5; Figure S6) and the absence of comp.1 in the polyphenol-rich, but protein-free HA from anoxic groundwater. Polyphenol-like fluorescence (comp.2) was predominant in efOM. This agrees with Kaiser and Kalbitz ${ }^{21}$, who proposed that mobile OM in topsoils and organic surface layers bears a vegetation-type signature due to the presence of lignin-derived phenols. The relative contribution of polyphenol-like fluorescence decreased after dialysis of efOM (comp.2 in * vs. ***; Figure S3A), thus pointing to a dialysis-induced loss of polyphenolic substances. Consequently, the results obtained for dialyzed efOM presumably underestimated the extent of polyphenol-dependent parameters as originally present in non-dialyzed efOM, e.g., its aromaticity and electron-donating capacity. We are aware that the fluorescence intensity, which is reflected by the component scores, is affected by multiple factors additional to fluorophore concentrations, e.g., quenching and changes in the molecular environment of the fluorophore ${ }^{19}$. However, we assume that intermolecular interactions (e.g., quenching) were not affected by dialysis considering the nearly constant scores of comp.1 and comp.3-5 in efOM (*vs. ***; Figure S3A). The fluorescence properties of efOM were well reversible upon changes in pH, which supports the general reversibility of $\mathrm{pH}$-induced changes in its molecular structure. 
Table S2. Measured, interpolated and reconstructed excitation-emission-matrices (EEM) and corresponding $\mathrm{pH}$ values of organic matter (OM)-containing solutions. efOM: soil effluent OM from an anoxic topsoil of a floodplain site (Table S1). *: instantly acidified soil column effluent. **: dialyzed *. ***: acidified **. EPS: extracellular polymeric substances from Bacillus subtilis. HA: humic acid from anoxic groundwater. lignin: sulfonated lignin. NRSME: normalized root square mean error (mean residuals between interpol. and reconstr. EEM). Reconstruction was conducted with a 5-component parallel factor analysis (Figure S3).

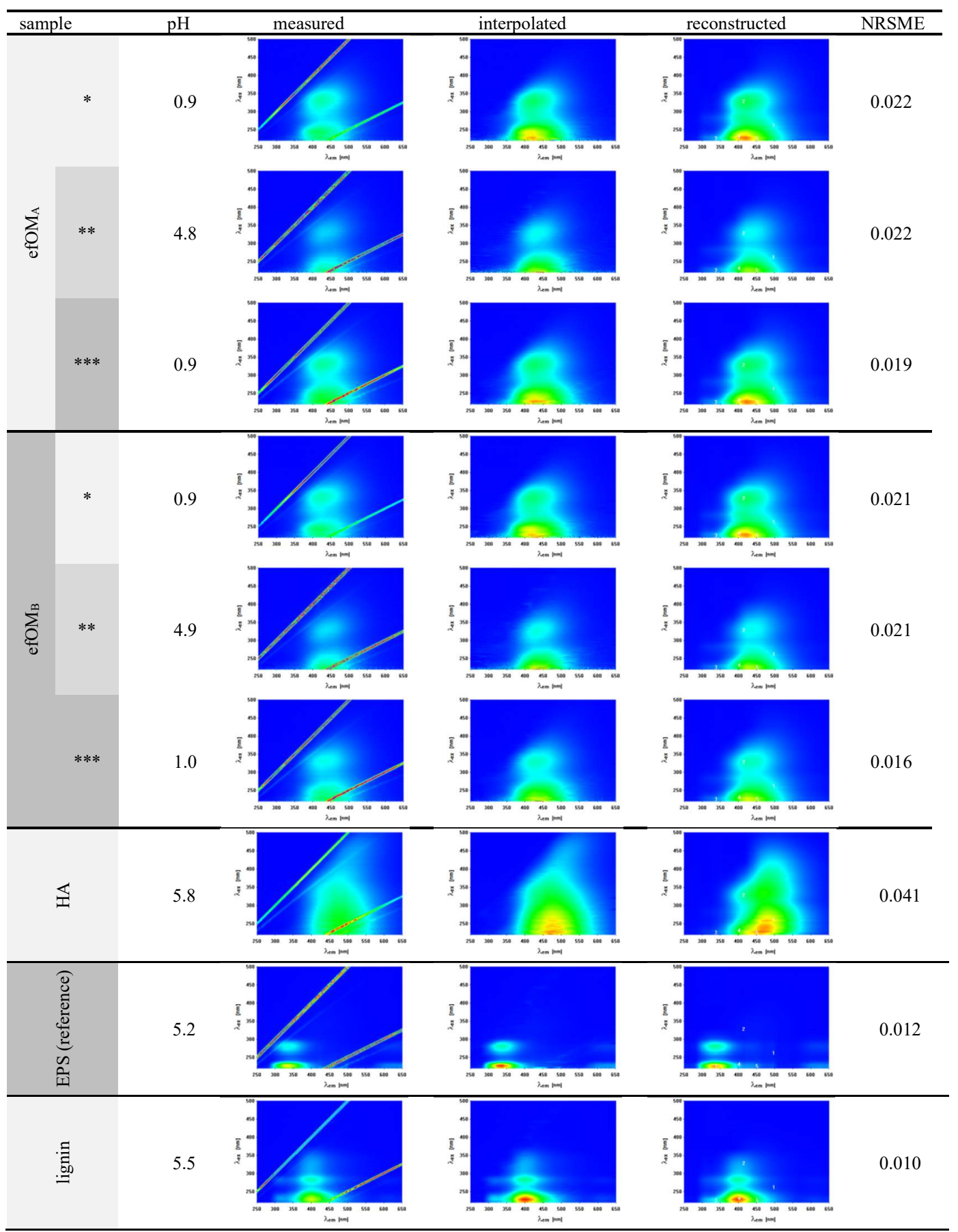

Solution $\mathrm{pH}$ was analyzed potentiometrically (Sentix 41+pH 197i, WTW). Excitation-emission-matrices (EEM) of aqueous OM solutions were obtained in a quartz cuvette (edge length: $1 \mathrm{~cm}$ ) with a fluorescence spectrophotometer (Cary Eclipse, Agilent). The samples were excited from $\lambda_{\text {exc }}=220-500 \mathrm{~nm}$ and emissions were recorded from $\lambda_{\mathrm{em}}=250-650 \mathrm{~nm}$, both in increments of $1 \mathrm{~nm}$. Repetitive analyses of the same samples yielded identical EEM and hence ruled out irradiation-induced changes in OM during analysis. EEM were corrected for inner filter-effects, ${ }^{22}$ which required UV-Vis absorption spectra (220-650 nm, increments of $1 \mathrm{~nm}$; Cary 50, Agilent). Rayleigh scattering and Raman scattering were removed via interpolation using a cubic spline function. The EEM were normalized on daily determined Raman units of ultrapure water. ${ }^{23}$ Nonnegativity constrained parallel factor analysis was applied to interpolated EEM. ${ }^{24,25}$ 
Table S3. Composition of the media used for (pre-)cultivation of Geobacter sulfurreducens and for the microbial reduction experiments.

\begin{tabular}{|c|c|c|c|c|c|}
\hline \multicolumn{3}{|r|}{ (pre-)cultivation } & \multicolumn{3}{|c|}{ reduction experiments } \\
\hline & solution & compound $\left(\mathrm{L}^{-1}\right)$ & & solution & compound $\left(\mathrm{L}^{-1}\right)$ \\
\hline A & $\begin{array}{l}\text { mineral } \\
\text { medium }\end{array}$ & $\begin{array}{l}1.0 \mathrm{~g} \mathrm{NaCl}^{(\geq 99.8 \%} \text {; Carl Roth) } \\
0.4 \mathrm{~g} \mathrm{MgCl}_{2} \times 6 \mathrm{H}_{2} \mathrm{O} \text { (p.a.; Merck) } \\
0.2 \mathrm{~g} \mathrm{KH}_{2} \mathrm{PO} 4(\geq 99.0 \% \text {; Sigma-Aldrich) } \\
0.25 \mathrm{~g} \mathrm{NH}_{4} \mathrm{Cl}(\geq 99.5 \% \text {; Carl Roth) } \\
0.5 \mathrm{~g} \mathrm{KCl}^{\text {(p.a.; Sigma-Aldrich) }} \\
0.15 \mathrm{~g} \mathrm{CaCl}_{2} \times 2 \mathrm{H}_{2} \mathrm{O} \text { (p.a.; Carl Roth) }\end{array}$ & $\mathrm{E}$ & $\begin{array}{l}\text { mineral } \\
\text { medium }\end{array}$ & $\begin{array}{l}110 \mathrm{mg} \mathrm{NaCl} \\
4.4 \mathrm{mg} \mathrm{MgCl}_{2} \times 6 \mathrm{H}_{2} \mathrm{O} \\
27.5 \mathrm{mg} \mathrm{NH}_{4} \mathrm{Cl} \\
55 \mathrm{mg} \mathrm{KCl} \\
1.7 \mathrm{mg} \mathrm{CaCl}_{2} \times 2 \mathrm{H}_{2} \mathrm{O} \\
1.6 \mathrm{mg} \mathrm{Na}_{2} \mathrm{SO}_{4} \text { (Sigma-Aldrich) }\end{array}$ \\
\hline B & $\begin{array}{c}\text { trace } \\
\text { elements }\end{array}$ & 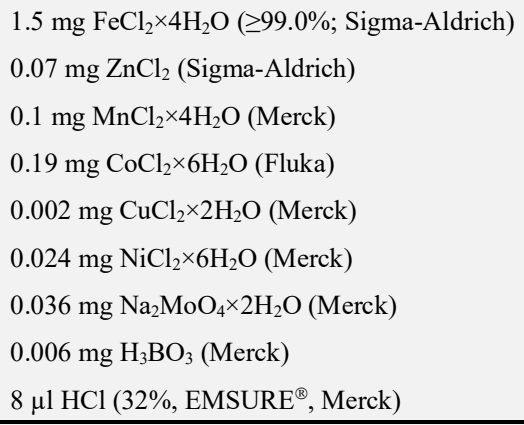 & $\mathrm{F}$ & $\begin{array}{c}\text { trace } \\
\text { elements }\end{array}$ & $\begin{array}{l}165 \mu \mathrm{g} \mathrm{FeCl}_{2} \times 4 \mathrm{H}_{2} \mathrm{O} \\
7.7 \mu \mathrm{g} \mathrm{ZnCl}_{2} \\
11 \mu \mathrm{g} \mathrm{MnCl}_{2} \times 4 \mathrm{H}_{2} \mathrm{O} \\
21 \mu \mathrm{g} \mathrm{CoCl}_{2} \times 6 \mathrm{H}_{2} \mathrm{O} \\
0.2 \mu \mathrm{g} \mathrm{CuCl}_{2} \times 2 \mathrm{H}_{2} \mathrm{O} \\
2.6 \mu \mathrm{g} \mathrm{NiCl}_{2} \times 6 \mathrm{H}_{2} \mathrm{O} \\
4 \mu \mathrm{g} \mathrm{Na}_{2} \mathrm{MoO}_{4} \times 2 \mathrm{H}_{2} \mathrm{O} \\
0.7 \mu \mathrm{g} \mathrm{H}_{3} \mathrm{BO}_{3} \\
0.9 \mu \mathrm{l} \mathrm{HCl}\end{array}$ \\
\hline $\mathrm{C}$ & $\begin{array}{l}\text { selenium- } \\
\text { tungsten }\end{array}$ & $\begin{array}{l}0.5 \mathrm{mg} \mathrm{NaOH} \text { (Sigma-Aldrich) } \\
0.003 \mathrm{mg} \mathrm{Na}_{2} \mathrm{SeO}_{3} \times 5 \mathrm{H}_{2} \mathrm{O} \text { (Sigma-Aldrich) } \\
1.25 \mathrm{mg} \mathrm{Na}_{2} \mathrm{Wo}_{4} \times 2 \mathrm{H}_{2} \mathrm{O} \text { (Sigma-Aldrich) }\end{array}$ & G & $\begin{array}{l}\text { selenium- } \\
\text { tungsten }\end{array}$ & $\begin{array}{l}55 \mu \mathrm{g} \mathrm{NaOH} \\
0.3 \mu \mathrm{g} \mathrm{Na}_{2} \mathrm{SeO}_{3} \times 5 \mathrm{H}_{2} \mathrm{O} \\
138 \mu \mathrm{g} \mathrm{Na}_{2} \mathrm{Wo}_{4} \times 2 \mathrm{H}_{2} \mathrm{O}\end{array}$ \\
\hline $\mathrm{D}$ & vitamins & $\begin{array}{l}25 \mu \mathrm{g} \text { cyanocobalamin (Fluka) } \\
25 \mu \mathrm{g} \text { p-aminobenzoic acid (Merck) } \\
5 \mu \mathrm{g} \mathrm{D}(+) \text { biotin (Merck) } \\
50 \mu \mathrm{g} \text { niacin (Merck) } \\
12.5 \mu \mathrm{g} \text { Ca-D(+)-pantothenate (Merck) } \\
50 \mu \mathrm{g} \text { thiamine hydrochlorid (Merck) } \\
125 \mu \mathrm{g} \text { pyridoxamine dihydrochloride (Fluka) }\end{array}$ & $\mathrm{H}$ & vitamins & $\begin{array}{l}2.8 \mu \mathrm{g} \text { cyanocobalamin } \\
2.8 \mu \mathrm{g} \text { p-aminobenzoic acid } \\
0.6 \mu \mathrm{g} \mathrm{D}(+) \text { biotin } \\
5.5 \mu \mathrm{g} \text { niacin } \\
1.4 \mu \mathrm{g} \mathrm{Ca}-\mathrm{D}(+) \text {-pantothenate (Merck) } \\
5.5 \mu \mathrm{g} \text { thiamine hydrochlorid } \\
13.8 \mu \mathrm{g} \text { pyridoxamine dihydrochloride }\end{array}$ \\
\hline
\end{tabular}

The strain was pre-cultivated in a mineral medium (Table S3A) that was supplemented with trace elements (Table S3B), selenite-tungsten (Table $\mathrm{S} 3 \mathrm{C}$ ), vitamins (Table S3D), $0.01 \mathrm{mM}$ cyclic adenosine monophosphate (cAMP; $\geq 98.5 \%$; Sigma-Aldrich), $1 \mathrm{mM} \mathrm{FeCl} 2 \times 4 \mathrm{H}_{2} \mathrm{O}$ ( $\geq 99 \%$; $\mathrm{Sigma}^{-}$ Aldrich), $10 \mathrm{mM}$ Na-acetate (p.a.; Merck), Fh, ${ }^{26}$ and buffered with $30 \mathrm{mM} \mathrm{NaHCO} 3$ (pH 6.8; Fluka; Germany). $10 \mathrm{~mL}$ of the pre-culture were transferred into $1 \mathrm{~L}$ cultivation medium containing the same ingredients as the pre-cultivation medium except for $50 \mathrm{mM}$ Na-fumarate as electron acceptor instead of Fh. The cultivation medium was buffered with $50 \mathrm{mM} \mathrm{NaHCO}_{3}$ (pH 6.8). After growth to the late exponential phase (7-14 d), the cells were harvested by centrifugation (15 min at $4400 \mathrm{~g}$ and $293 \mathrm{~K}$; Avanti J-E with rotor JA-10, Beckman-Coulter, USA). The cell pellet was re-suspended in acetate-free low salt medium (Table S3E), centrifuged and repeatedly re-suspended in $50 \mathrm{~mL}$ of acetate-free low salt medium. This concentrated cell suspension was subsequently used in the microbial Fe(III) reduction experiments (see explanations in the manuscript). 
OM-free ferrihydrite (= reference for the relative reduction rates)

abiotic control \#1 [no Geobacter sulfurreducens]

\section{abiotic control \#2} [no acetate]

biotic control [Fe(III) citrate]
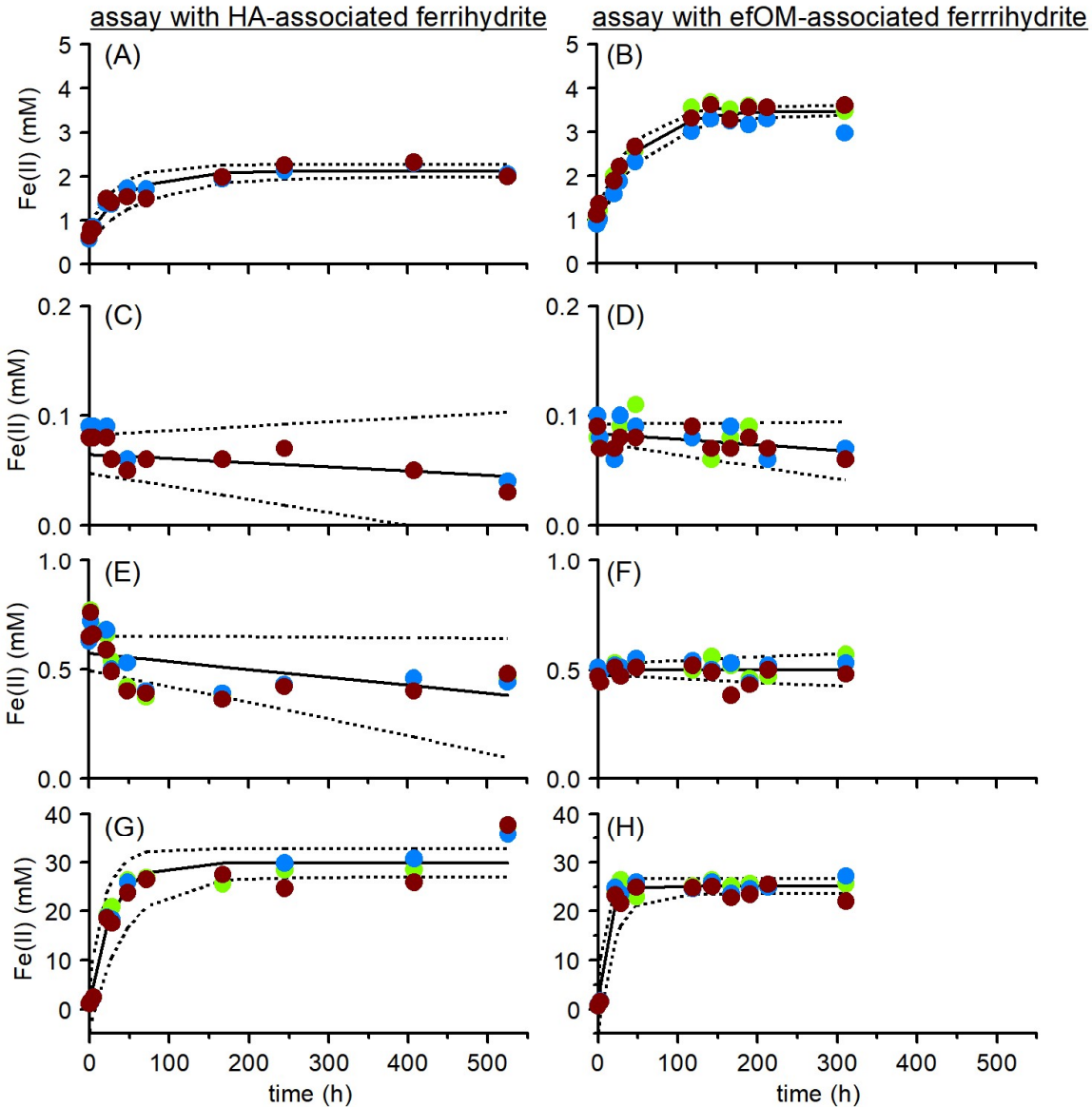

Figure S4. Evolution of Fe(II) during (A, B) the microbial reduction of OM-free ferrihydrite and in (C-F) negative controls and in (G, H) positive controls, in which the following modifications from the standard protocol were applied: abiotic control \#1: absence of Geobacter sulfurreducens $(0.22 \mu \mathrm{m}$-filtration of the cell suspension before its inoculation) abiotic control \#2: no addition of Na-acetate (energy and carbon source). biotic control: Fe-source = Fe(III) citrate $\left(\mathrm{C}_{6} \mathrm{H}_{5} \mathrm{FeO}_{7}\right.$; AppliChem $\left.\mathrm{GmbH}\right)$. Symbols depict mean values of three replicate batch experiments. Solid lines depict the Fe(II) concentrations predicted from fitted rate constants $(k)$, initial and maximum Fe(II) concentrations ( $c_{I N I T}$ and $c_{M A X}$, respectively) presented in Table S6. Dashed lines depict the $95 \%$ confidence interval that arose due to the uncertainty of the fitted parameters. 


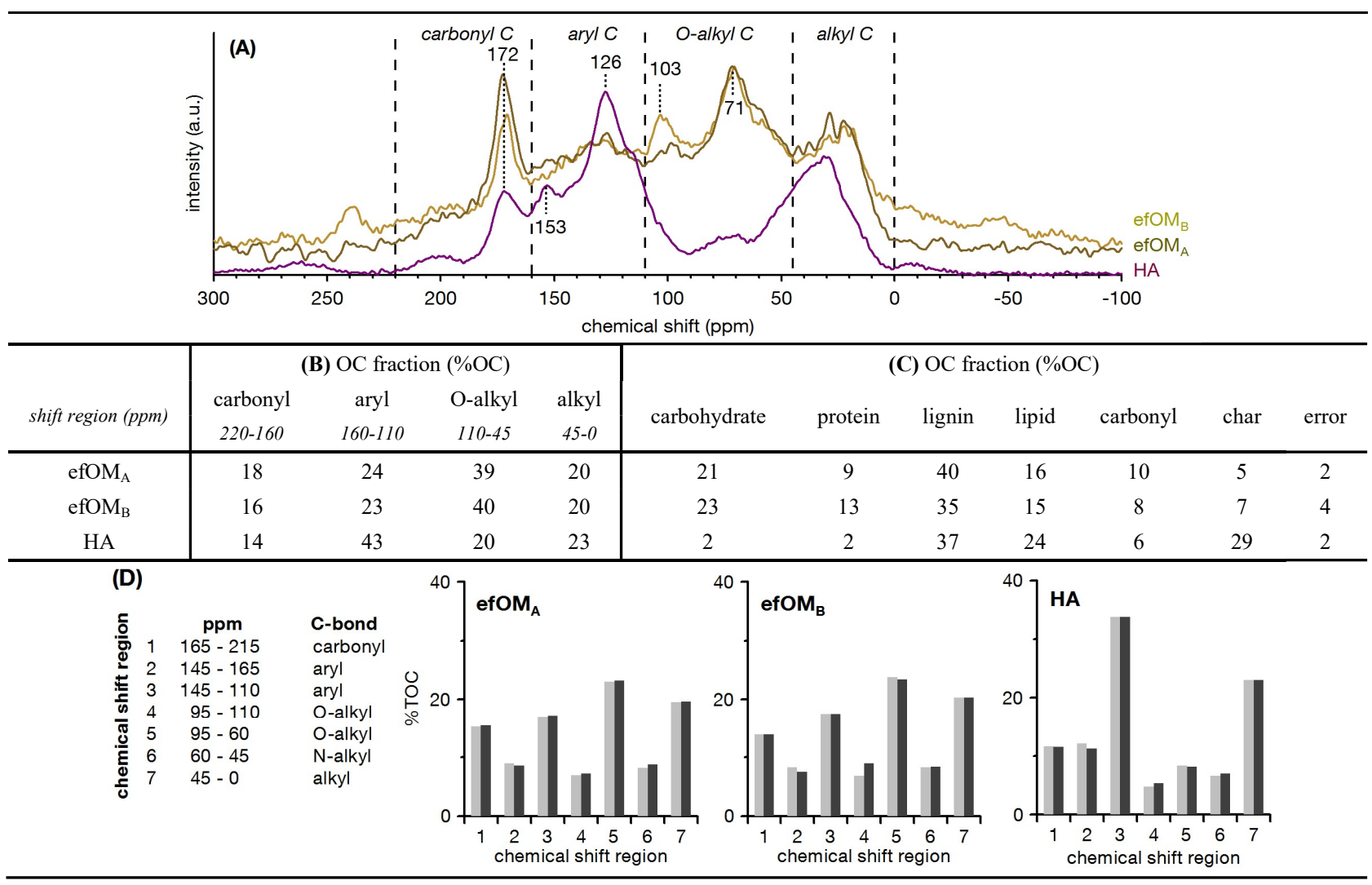

Figure S5. (A) Solid-state ${ }^{13} \mathrm{C}$-NMR spectra of soil effluent organic matter (efOM) from an anoxic topsoil of a floodplain site (Table S1) and humic acid (HA) from anoxic groundwater. (B) Relative contributions of characteristic chemical bonds of organic carbon (OC). (C) Relative contributions of selected biomolecules to efOM and HA as derived from the extended biomolecular mixing mode ${ }^{27}$ with fixed $\mathrm{N}$ contents (Table 1). ABB: independent replicates. error: sum of absolute deviations between predicted and measured integrals (Figure S5D).

Solid-state ${ }^{13} \mathrm{C}$-NMR spectroscopy (DSX 200, Bruker) was used in cross-polarization magic angle spinning mode with a ${ }^{13} \mathrm{C}$ resonance frequency of $50.32 \mathrm{MHz}$ and a spinning speed of $5.0 \mathrm{kHz}$. A ramped ${ }^{1} \mathrm{H}$-pulse starting at $100 \%$ to $50 \%$ of the initial power was used during a contact time of $1.0 \mathrm{~ms}$ to prevent spin modulation during the Hartmann-Hahn contact. Pulse delays of $400 \mathrm{~ms}$ were used. A line broadening of $50 \mathrm{~Hz}$ was applied to the spectra. The ${ }^{13} \mathrm{C}$ chemical shifts were calibrated relative to tetramethylsilane. The relative contribution of characteristic compounds was estimated by the extended biomolecular mixing model (MMM). The MMM is a linear combination fitting of selected OM references (carbohydrate, lignin, protein, lipid, char, pure carbonyl) to reconstruct the measured distribution of integrated band intensities in fixed chemical shift regions of ${ }^{13} \mathrm{C}-\mathrm{NMR}$ spectra. ${ }^{27}$

The ${ }^{13} \mathrm{C}$-NMR spectra of efOM revealed two dominant bands at $\sim 172 \mathrm{ppm}$ (carbonyl bonds in carboxylic groups, amides and aliphatic esters) ${ }^{28}$ and at $\sim 71 \mathrm{ppm}$ (hemicelluloses; Figure S5A) ${ }^{29}$ Increased band intensities at $\sim 126 \mathrm{ppm}$ and at $\sim 153 \mathrm{ppm}$ point to the presence of polycyclic aromatic structures ${ }^{30}$ and $\mathrm{O}$-substituted aromatic $\mathrm{C}$ (phenol C) $)^{31}$ in HA, respectively. In absence of distinct bands between $160-140$ ppm, bands between 120 - 90 ppm cannot be assigned to phenol C, but rather to O-alkyl C in carbohydrate-derived structures, ${ }^{29}$ which applied to the band at $\sim 103 \mathrm{ppm}$ in the spectra of efOM.

The relative content of carbonyl, aryl, O-alkyl and alkyl C was nearly identical in the two independent replicates of efOM (Figure S5B). In comparison, HA contained more aromatic $\mathrm{C}$ at the expense of O-alkyl C. Using the MMM approach, ${ }^{13} \mathrm{C}-\mathrm{NMR}$ spectra were translated into a standardized molecular composition of natural OM. ${ }^{27,32} \mathrm{We}$ obtained a good match between measured and calculated integrals (Figure S5D) with relative errors of $2-4 \%$ of the total intensity (Figure S5C), which was similar to previous studies. ${ }^{27}$ In clear contrast to efOM, HA contained almost no proteins and carbohydrates. This finding was in agreement with the corresponding $\mathrm{C} / \mathrm{N}$ ratios (Table 1) and can be rationalized by the fact that the fitting procedure was constrained to the measured $\mathrm{N}$ content. Nevertheless, the good fits of the constrained MMM supported that proteins were the exclusive $\mathrm{N}$-carrying biomolecules in these OM. Char was present in efOM and HA, but much more pronounced in the latter. Char is enriched in small size-fractions ${ }^{27}$ and is therefore potentially mobile in porous media. However, the preferential selection of strong hydrophobic molecules during extraction of HA from anoxic groundwater on hydrophobic resins (XAD-8) ${ }^{33}$ very likely resulted in an enrichment of char in HA. 


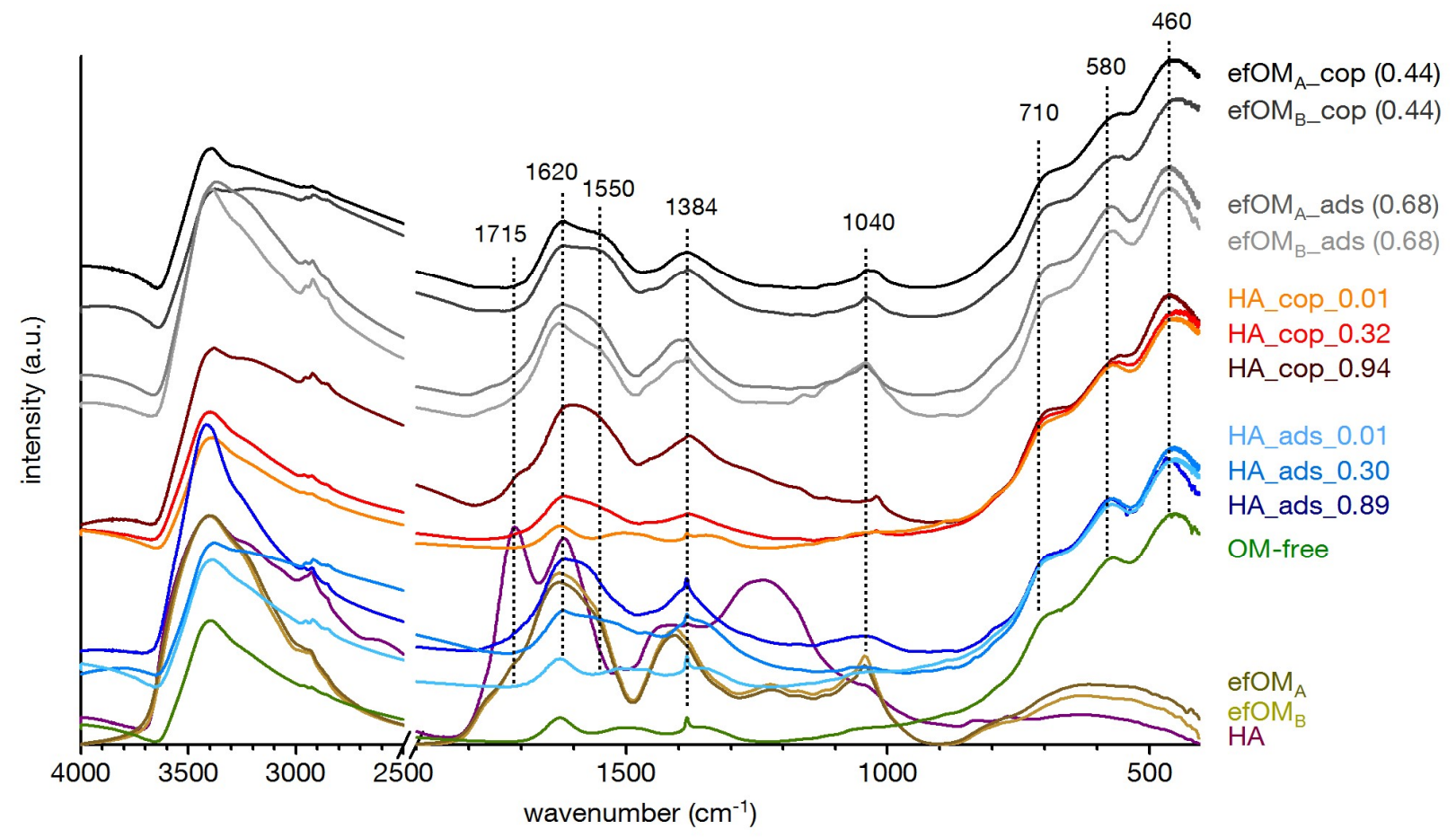

Figure S6. Fourier-transform infrared (FTIR) spectra of OM-free and organo-mineral ferrihydrite with adsorbed (ads) and coprecipitated (cop) humic acids (HA) from anoxic groundwater ${ }^{33}$ and soil effluent organic matter (efOM) from an anoxic topsoil of a floodplain site (Table S1). A/B: independent replicates. The values in the sample name denote the molar OC/Fe ratio, which was set in the corresponding suspension. Dashed lines depict wavenumbers of interest.

The FTIR spectra were recorded in transmission mode using a Nicolet iS10 spectrometer (Thermo Fisher Scientific). The samples ( 1 mg) were mixed with $\mathrm{KBr}$ ( $\sim 250 \mathrm{mg}$; FTIR spectroscopy grade, Merck), mortared and pressed to pellets. The pellets were measured at wavenumbers from 4000 to $400 \mathrm{~cm}^{-1}$ with 16 scans per spectrum at a resolution of $4 \mathrm{~cm}^{-1}$. The spectra were baseline-corrected and normalized to maximum intensity. Independent of the OM type (HA vs. efOM), its mode of association (adsorbed vs. coprecipitated) and its relative content, all synthesized ferrihydrites (Fh) exhibited bands at $\sim 710, \sim 580$ and $\sim 460 \mathrm{~cm}^{-1}$, which is characteristic of 6-line Fh. ${ }^{34}$ The abundance of 6-line Fh as exclusive mineral phase is in agreement with the findings from X-ray diffractometry (Figure 1). A weak band at $1384 \mathrm{~cm}^{-1}$ indicated the presence of nitrate, ${ }^{34}$ which occasionally resided at the Fh surface despite dialysis. However, given the very strong intensity of surface-bound nitrate in transmission FTIR spectra, we consider this amount of residual nitrate as negligible.

Increasing relative amounts of HA in the synthesis suspensions were accompanied by stronger bands at $\sim 1600$ and $\sim 1400 \mathrm{~cm}^{-1}$ in the spectra of the corresponding HA-associated Fh. These bands reflect the absorbance of carboxyl groups that are present in the HA molecules. ${ }^{35}$ Consequently, higher $\mathrm{OC} / \mathrm{Fe}$ ratios in the initial synthesis suspensions resulted in higher OC/Fe ratios in the synthesized organo-mineral Fh. Upon reaction with Fh, protonated carboxyl groups, which were present in unreacted HA $\left(\sim 1715 \mathrm{~cm}^{-1}\right)$ completely vanished. Compared to HA, efOM reproducibly exhibited stronger bands that are characteristic of proteins (N-H deformation (amide II) at $\sim 1550 \mathrm{~cm}^{-1}$ ) and polysaccharides (overlapped C-O-C and C-OH stretches at $\sim 1040 \mathrm{~cm}^{-1}$ ). These bands were also more pronounced in the spectra of efOM-associated Fh (particularly with adsorbed efOM), which points to the fact that proteins and polysaccharides from efOM effectively associate with Fe-rich precipitates. $^{12}$ 
Table S4. C/N and C/S ratios and electron-accepting capacities (EAC) of selected OM specimens. FA: fulvic acids from the same anoxic groundwater the humic acid used in this study was obtained from. efOM: soil effluent organic matter from an anoxic topsoil of an agriculture site (ploughed horizon; Ap). [1] and [2]: independent replicates. WEOM[1]: water-extractable OM from forest floor, which was used in adsorption/coprecipitation experiments with ferrihydrite. ${ }^{36}$ WEOM[2]: water-extractable OM from forest floor, which was used in microbial reduction experiments with organo-mineral ferrihydrite. ${ }^{37,38} . \pm$ : standard deviation from arithmetic mean. Grey values: Normalization to OC concentrations invalid as EAC was dominated by Fe(III).

\begin{tabular}{|c|c|c|c|c|c|}
\hline \multirow{2}{*}{ sample } & $\mathrm{C} / \mathrm{N}$ & $\mathrm{C} / \mathrm{S}$ & \multicolumn{2}{|c|}{ measured EAC } & $\mathrm{EAC}_{\mathrm{OM}}{ }^{\mathrm{a}}$ \\
\hline & \multicolumn{2}{|c|}{$\mathrm{g} \mathrm{g}^{-1}$} & $\mathrm{mmol} \mathrm{e}^{-}(\mathrm{mol} \mathrm{OC})^{-1}$ & $\mathrm{~mol} \mathrm{e}^{-}(\mathrm{mol} \mathrm{Fe})^{-1}$ & $\mu \mathrm{mol} \mathrm{e}^{-}\left(\mathrm{g} \mathrm{OM}^{-1}\right.$ \\
\hline FA & n.p. ${ }^{b}$ & 47 & $10.8 \pm 0.7$ & $\mathrm{Fe}<$ d. $1 .^{\mathrm{c}}$ & $452 \pm 28$ \\
\hline $\operatorname{efOM}_{\mathrm{Ap}}[1]$ & 26 & 52 & $120.0 \pm 3.8$ & $0.99 \pm 0.02$ & n.p. ${ }^{\mathrm{d}}$ \\
\hline $\mathrm{efOM}_{\mathrm{Ap}}[2]$ & 21 & 50 & $89.0 \pm 3.8$ & $1.10 \pm 0.01$ & $213 \pm 18$ \\
\hline WEOM[1] & 18 & 170 & $12.1 \pm 0.3$ & $25.16 \pm 0.39$ & $394 \pm 8$ \\
\hline WEOM[2] & 12 & 173 & $32.0 \pm 1.0$ & $22.85 \pm 0.44$ & $934 \pm 27$ \\
\hline
\end{tabular}

a corrected for contribution of Fe(III) to EAC (assuming Fe Total $=\mathrm{Fe}(\mathrm{III}))$ : EACoM $=\left(\right.$ measured EAC $\left[\mu \mathrm{mol} \mathrm{e}^{-} \mathrm{L}^{-1}\right]-$ Fe concentration $\left.\left[\mu \mathrm{mol} \mathrm{L}^{-1}\right]\right) * \mathrm{OM}$ concentration $\left[\mathrm{g} \mathrm{L}{ }^{-1}\right]^{-1}$

${ }^{\mathrm{b}} \mathrm{N}$ below detection limit

c detection limit: $4 \mu \mathrm{g} \mathrm{L}{ }^{-1}$

${ }^{\mathrm{d}} \mathrm{EAC}\left(152 \pm 3 \mu \mathrm{mol} \mathrm{e}-\mathrm{L}^{-1}\right)<\mathrm{Fe}\left(154 \pm 2 \mu \mathrm{mol} \mathrm{L}{ }^{-1}\right)$

Water-extractable OM (WEOM) was obtained by extracting $<2 \mathrm{~mm}$-sieved organic surface layers (Oi and Oa horizon) of a Podzol under spruce (Picea abies L.; near Freising, Germany) with de-ionized water at a liquid-to-solid ratio of $4.76 \mathrm{~cm}^{3} \mathrm{~g}^{-1}$. The forest floor was sampled at the same site during summer (WEOM[1]) and after snowmelt (WEOM[2]). The extracts were shaken for $16 \mathrm{~h}$ at room temperature and then centrifuged $(1 \mathrm{~h}$ at $4650 \times \mathrm{g})$. The supernatant was filtered through polyvinylidene fluoride $0.45 \mu \mathrm{m}$-cutoff membranes (Durapore, Merck), concentrated in low temperature rotary evaporators, and freeze-dried. More details can be found elsewhere. ${ }^{36,37}$ 

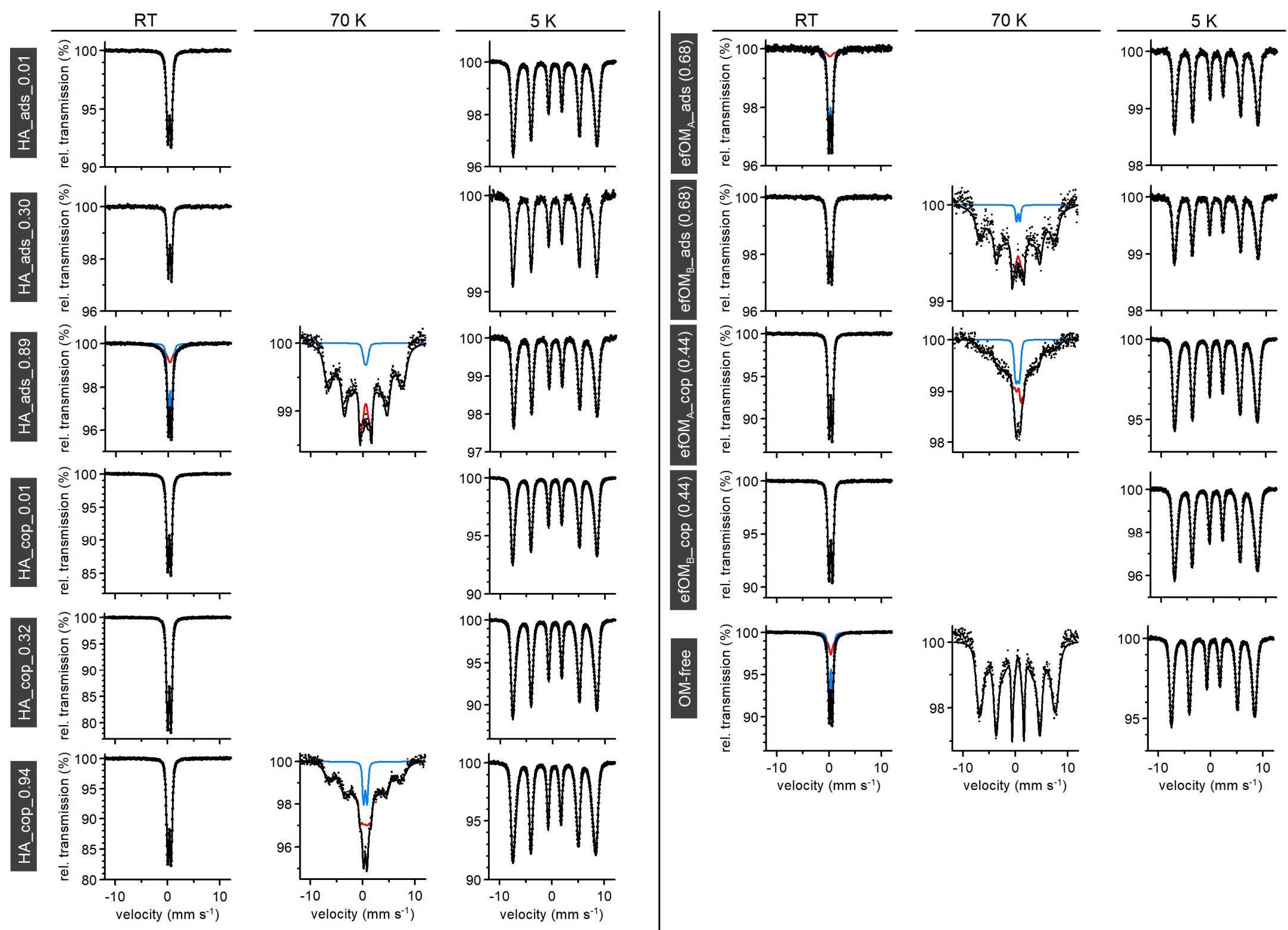

Figure S7. Mössbauer spectra of organo-mineral and OM-free ferrihydrite with adsorbed (ads) and coprecipitated (cop) organic matter (OM) recorded at room temperature (RT), $70 \mathrm{~K}$ and $5 \mathrm{~K}$. efOM: soil effluent OM from an anoxic topsoil of a floodplain site (Table S1). ${ }_{\mathrm{AB}}$ : independent replicates. HA: humic acid from anoxic groundwater. The values in the sample name denote the molar OC/Fe ratio, which was set in the corresponding suspension. Black symbols depict measured data and black graphs depict the sum fit according to component details given in Table S5. The blue graphs depict the contribution of a non-magnetically split component to the sum fit. The red graphs depict the contribution of a magnetically split component to the sum fit. 
Table S5. Center shifts $(\delta)$, quadrupole splittings $\left(\Delta \mathrm{E}_{\mathrm{Q}}\right)$, quadrupole shifts $(\varepsilon)$ and magnetic hyperfine fields $\left(\mathrm{B}_{\mathrm{hf}}\right)$ as obtained from fitted ${ }^{57} \mathrm{Fe}-\mathrm{Mössbauer}$ spectra of organo-mineral ferrihydrite, which were recorded at room temperature (RT), $5 \mathrm{~K}$ and $70 \mathrm{~K}$. Refer to Figure S7 for the corresponding spectra and fits. HA: humic acids from anoxic groundwater. efOM: soil effluent organic matter from an anoxic topsoil of a floodplain site (Table S1). As: independent replicates. The values in the sample name denote the molar OC/Fe ratio, which were set in the corresponding suspensions. *: additional background component required in RT spectra fits. n.a.: not analyzed.

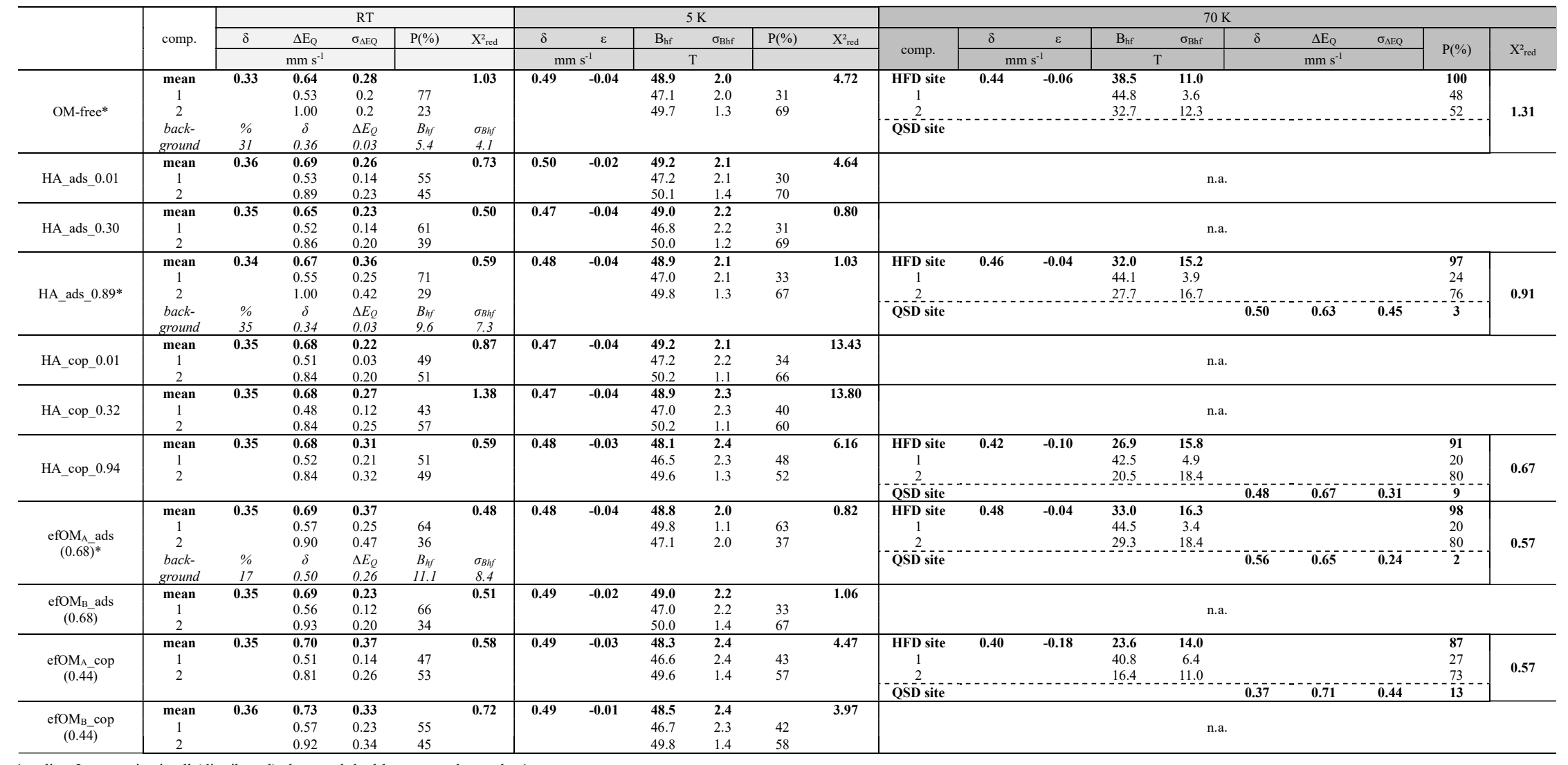

All line-1 to line-2 area ratios in all (distributed) elemental doublets were taken to be 1 .

$\mathrm{P}($ in \%) is the weight factor for a given Gaussian component in a given quadrupole splitting distribution (QSD) or hyperfine field distribution (HFD).

$\Delta \mathrm{E}_{\mathrm{Q}}=$ if bold: average magnitude of the quadrupole splitting in a given QSD of a given doublet spectral component; otherwise: the center (or position) of a Gaussian component in the QSD of a given doublet spectral componen

$\mathrm{X}^{2}{ }_{\text {red }}$ is the reduced chi-squared value for the fit: chi-squared divided by the number of degrees of freedom. It has an ideal value of 1 for a correct model.

All $\delta$ are given with respect to the center shift of metallic Fe at $295 \mathrm{~K}$. component.

$\varepsilon=$ average magnitude of the slave distribution of quadrupole shifts (epsilons) associated to a given HFD of a given sextet spectral component.

All fits relied on the Voigt-based fitting ${ }^{39}$ and were conducted with the Recoil ${ }^{\mathrm{TM}}$ software. Two Gaussian components (comp. 1 and 2 ) were used to achieve sufficiently good fits. Both components shared the same $\delta(\mathrm{RT}, 70 \mathrm{~K}, 5 \mathrm{~K})$ and $\varepsilon(70 \mathrm{~K}, 5 \mathrm{~K})$, while the center positions of $\Delta \mathrm{E}_{\mathrm{Q}}(\mathrm{RT})$ and $\mathrm{B}_{\mathrm{hf}}(70 \mathrm{~K}, 5 \mathrm{~K})$, the corresponding standard deviations $(\sigma)$ and weight factors $(\mathrm{P}(\%))$ were fitted to the observed data. Three samples (denoted with *) required an additional background component to obtain physically reasonable fits for their Mössbauer spectra at RT. 
Table S6. Absolute values of fitted rate constants $(k)$, maximum Fe(II) concentrations $\left(c_{\text {MAX }}\right)$ and initial Fe(II) concentrations $\left(c_{I N I T}\right)$ and the resulting half-life of ferrihydrite, which parameterized the observed microbial Fe(III) reduction in the reduction experiments. Controls: w/o G. sulfurreducens: absence of Geobacter sulfurreducens $(0.22 \mu \mathrm{m}$-filtration of the cell suspension before inoculation), w/o acetate: no addition of Na-acetate (= energy and carbon source), Fe(III) citrate: $\mathrm{Fe}$-source $=30 \mathrm{mM} \mathrm{Fe}(\mathrm{III})$ citrate $\left(\mathrm{C}_{6} \mathrm{H}_{5} \mathrm{FeO}_{7}\right.$; AppliChem $\left.\mathrm{GmbH}\right)$. Fh: ferrihydrite. HA: humic acids from anoxic groundwater. efOM: soil effluent organic matter from an anoxic topsoil of a floodplain site (Table S1). Error bars denote the standard error. The raw data on the evolution of Fe(II) over time and the confidence interval of each fit can be found in Figure 3 (HA- and efOM-associated Fh) and in Figure S4 (OM-free Fh, controls).

\begin{tabular}{|c|c|c|c|c|c|c|c|}
\hline & & & $\begin{array}{l}\text { molar } \\
\mathrm{OC} / \mathrm{Fe}\end{array}$ & $k\left(\mathrm{~h}^{-1}\right)$ & $c_{M A X}(\mathrm{mM})$ & $c_{I N I T}(\mathrm{mM})$ & half-life (h) \\
\hline \multirow{10}{*}{ 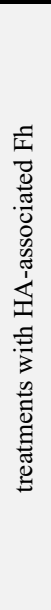 } & \multirow{3}{*}{ controls } & $\begin{array}{c}\text { w/o } G . \\
\text { sulfurreducens }\end{array}$ & & $-0.000010 \pm 0.000009$ & $4.0^{\mathrm{b}}$ & $0.0647 \pm 0.0078$ & \multirow[b]{3}{*}{$18.1 \pm 3.1$} \\
\hline & & w/o acetate & & $-0.000106 \pm 0.000045$ & $4.5^{\mathrm{b}}$ & $0.574 \pm 0.035$ & \\
\hline & & $\mathrm{Fe}(\mathrm{III})$ citrate & & $0.0383 \pm 0.0066$ & $29.9 \pm 1.3$ & $-0.4 \pm 2.0$ & \\
\hline & reference $^{\mathrm{a}}$ & OM-free Fh & & $0.0213 \pm 0.0032$ & $2.119 \pm 0.065$ & $0.706 \pm 0.078$ & $32.5 \pm 4.9$ \\
\hline & \multirow{6}{*}{ treatments } & \multirow{3}{*}{$\begin{array}{c}\text { Fh with } \\
\text { adsorbed HA }\end{array}$} & 0.01 & $0.00651 \pm 0.00063$ & $1.896 \pm 0.030$ & $0.874 \pm 0.033$ & $106.4 \pm 10.3$ \\
\hline & & & 0.30 & $0.00725 \pm 0.00055$ & $2.897 \pm 0.071$ & $0.894 \pm 0.071$ & $95.6 \pm 7.2$ \\
\hline & & & 0.89 & $0.01157 \pm 0.00053$ & $3.934 \pm 0.040$ & $1.150 \pm 0.060$ & $59.9 \pm 2.7$ \\
\hline & & \multirow{3}{*}{$\begin{array}{c}\text { Fh } \\
\text { coprecipitated } \\
\text { with HA }\end{array}$} & 0.01 & $0.00869 \pm 0.00079$ & $2.528 \pm 0.052$ & $0.871 \pm 0.045$ & $79.8 \pm 7.3$ \\
\hline & & & 0.32 & $0.01082 \pm 0.00065$ & $3.688 \pm 0.059$ & $0.694 \pm 0.055$ & $64.1 \pm 3.9$ \\
\hline & & & 0.96 & $0.0224 \pm 0.0013$ & $3.769 \pm 0.050$ & $0.782 \pm 0.062$ & $30.9 \pm 1.8$ \\
\hline \multirow{8}{*}{ 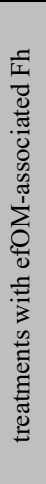 } & \multirow{3}{*}{ controls } & $\begin{array}{c}\text { w/o G. } \\
\text { sulfurreducens }\end{array}$ & & $-0.000013 \pm 0.000007$ & $4.0^{\mathrm{b}}$ & $0.0837 \pm 0.0038$ & \\
\hline & & w/o acetate & & $-0.000001 \pm 0.000021$ & $4.5^{\mathrm{b}}$ & $0.500 \pm 0.011$ & \\
\hline & & $\mathrm{Fe}(\mathrm{III})$ citrate & & $0.094 \pm 0.019$ & $25.08 \pm 0.71$ & $-1.5 \pm 1.6$ & $7.4 \pm 1.5$ \\
\hline & reference ${ }^{a}$ & OM-free Fh & & $0.0204 \pm 0.0015$ & $3.480 \pm 0.046$ & $0.998 \pm 0.069$ & $34.0 \pm 2.4$ \\
\hline & \multirow{4}{*}{ treatments } & \multirow{2}{*}{$\begin{array}{c}\text { Fh with } \\
\text { adsorbed efOM }\end{array}$} & A: 0.68 & $0.00570 \pm 0.00022$ & $4.683 \pm 0.079$ & $0.539 \pm 0.058$ & $121.7 \pm 4.6$ \\
\hline & & & B: 0.69 & $0.00338 \pm 0.00012$ & $5.01 \pm 0.10$ & $0.442 \pm 0.054$ & $205.2 \pm 7.5$ \\
\hline & & \multirow{2}{*}{$\begin{array}{c}\text { Fh } \\
\text { coprecipitated } \\
\text { with efOM }\end{array}$} & A: 0.44 & $0.0311 \pm 0.0027$ & $4.009 \pm 0.056$ & $1.294 \pm 0.097$ & $22.3 \pm 1.9$ \\
\hline & & & B: 0.44 & $0.0294 \pm 0.0026$ & $3.756 \pm 0.056$ & $0.965 \pm 0.096$ & $23.6 \pm 2.1$ \\
\hline
\end{tabular}

a reference to which the relative rate constants of the Fh-treatments with HA and efOM were normalized to (Figure 3 )

b fixed values (not fitted) 

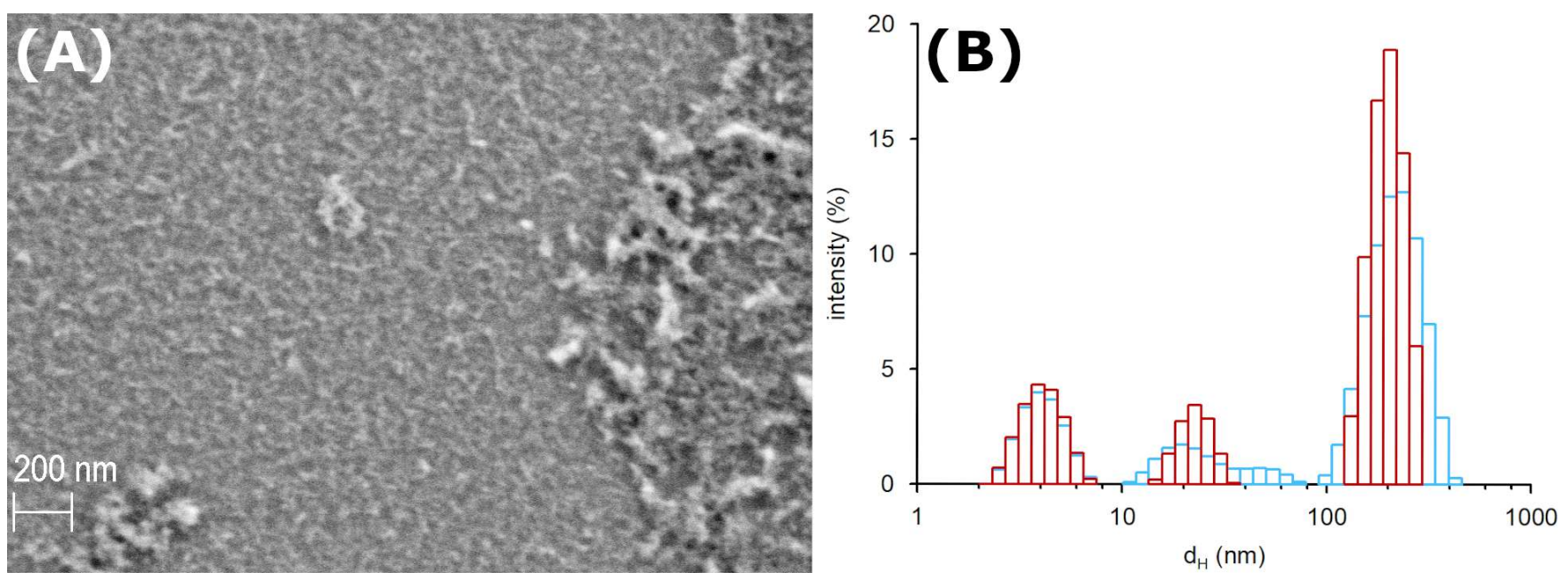

Figure S8. (A) Image from scanning electron microscopy (SEM) and (B) intensity histogram with hydrodynamic diameter $\left(\mathrm{d}_{\mathrm{H}}\right)$ distributions obtained from dynamic light scattering (DLS) analysis (two replicate measurements: dark red, blue) of OM-free 61-ferrihydrite (Fh), which were initially synthesized for the microbial reduction experiments.

For SEM, $10 \mu \mathrm{l}$ of Fh suspension were air-dried on a Si wafer. Analysis was conducted with an ULTRA PLUS field emission scanning electron microscope (Zeiss). For DLS, the Fh suspension was analyzed in backscattering mode (Nano ZS, Malvern Instruments, UK).

Variably sized aggregates were observed within the suspension containing the initial OM-free 61-Fh, which were synthesized for the microbial reduction experiments. The overwhelming majority of the aggregates was comparably small $(<10 \mathrm{~nm})$ and therefore difficult to capture with SEM and DLS to allow for a reliable quantification of the aggregate size distribution. Considering that the scattering intensity is inversely proportional to the sixth power of the radius for particles much smaller than the wavelength of the laser (here: $633 \mathrm{~nm}$ ), ${ }^{40}$ the number of Fh aggregates $<10 \mathrm{~nm}$ clearly exceeds the number of aggregates $>10 \mathrm{~nm}$ (Figure S8B). The apparent appearance of Fh aggregates $>10 \mathrm{~nm}$ in SEM images (Figure S8A) might be related to the superposition of Fh aggregates and additional aggregation processes as a result of the drying of the suspension at the wafer. In contrast, drying of the suspension was not required for DLS analysis thus avoiding such artifacts. 


\section{References}

1. German Institute for Standardization Soil quality - Determination of effective cation exchange capacity and base saturation level using barium chloride solution. In DIN EN ISO 11260:2011; German Institute for Standardization, Ed.; Berlin, 2011.

2. Harris, D.; Horwath, W. R.; van Kessel, C. Acid fumigation of soils to remove carbonates prior to total organic carbon or carbon-13 isotopic analysis. Soil Sci. Soc. Am. J. 2001, 65, 1853-1856; DOI

3. Mehra, O. P.; Jackson, M. L. Iron oxide removal from soils and clays by a dithionite-citrate system buffered with sodium carbonate. In Proceedings of the $7^{\text {th }}$ National Conference on Clays and Clay Minerals; Ingerson, E., Ed.; Pergamon Press: London, 1960; pp 317-327.

4. Fritzsche, A.; Pagels, B.; Totsche, K. U. The composition of mobile matter in a floodplain topsoil: A comparative study with soil columns and field lysimeters. J. Plant Nutr. Soil Sci. 2016, 179, 18-28; DOI 10.1002/jpln.201500169.

5. Fritzsche, A. Variably sized Fe oxide colloids from a soil effluent - Insights into composition, aggregation and reactivity. Ph.D. Dissertation, Friedrich-Schiller-University Jena, Jena, 2011.

6. Kieft, T. L.; Soroker, E.; Firestone, M. K. Microbial biomass response to a rapid increase in water potential when dry soil is wetted. Soil Biol. Biochem. 1987, 19, 119-126; DOI 10.1016/0038-0717(87)90070-8.

7. Lehmann, K.; Lehmann, R.; Totsche, K. U. Event-driven dynamics of the total mobile inventory in undisturbed soil account for significant fluxes of particulate organic carbon. Science of the Total Environment 2021, 756, DOI 10.1016/j.scitotenv.2020.143774.

8. Singer, P. C.; Stumm, W. Acidic mine drainage. Rate-determining step. Science 1970, 167, 1121-1123; DOI 10.1126/science.167.3921.1121.

9. Loeppert, R. H.; Inskeep, W. P. Colorimetric determination of ferrous iron and ferric iron by the 1,10-phenanthroline method. In Methods of Soil Analysis, Part 3. Chemical Methods; Sparks, D. L., Ed.; ASA: Madison, 1996; pp 659-661.

10. German Institute for Standardization. German standard methods for the examination of water, waste water and sludge; physical and physico-chemical parameters; determination of the oxidation reduction (redox) potential. In DIN 38404-6; Beuth Verlag: Berlin, 1984.

11. Cogger, C. G.; Kennedy, P. E.; Carlson, D. Seasonally saturated soils in the Puget Lowland 2. Measuring and interpreting redox potentials. Soil Sci. 1992, 154, 50-58; DOI 10.1097/00010694-199207000-00007.

12. Fritzsche, A.; Schröder, C.; Wieczorek, A. K.; Handel, M.; Ritschel, T.; Totsche, K. U. Structure and composition of Fe-OM co-precipitates that form in soil-derived solutions. Geochim. Cosmochim. Acta 2015, 169, 167-183; DOI 10.1016/j.gca.2015.07.041.

13. Cornell, R. M.; Schwertmann, U. The Iron Oxides. 2nd ed.; Wiley-VCH: Weinheim, Germany, 2003.

14. Mobed, J. J.; Hemmingsen, S. L.; Autry, J. L.; McGown, L. B. Fluorescence characterization of IHSS humic substances: Total luminescence spectra with absorbance correction. Environ. Sci. Technol. 1996, 30, 3061-3065; DOI 10.1021/es9601321.

15. Ritschel, T.; Totsche, K. U. Quantification of pH-dependent speciation of organic compounds with spectroscopy and chemometrics. Chemosphere 2017, 172, 175-184; DOI 10.1016/j.chemosphere.2016.12.145.

16. Borisover, M.; Lordian, A.; Levy, G. J. Water-extractable soil organic matter characterization by chromophoric indicators: Effects of soil type and irrigation water quality. Geoderma 2012, 179, 28-37; DOI 10.1016/j.geoderma.2012.02.019.

17. Ohno, T.; Bro, R. Dissolved organic matter characterization using multiway spectral decomposition of fluorescence landscapes. Soil Sci. Soc. Am. J. 2006, 70, 2028-2037; DOI 10.2136/sssaj2006.0005.

18. McGarry, S. F.; Baker, A. Organic acid fluorescence: Applications to speleothem palaeoenvironmental reconstruction. Quat. Sci. Rev. 2000, 19, 1087-1101; DOI 10.1016/s0277-3791(99)00087-6.

19. Chen, J.; Gu, B. H.; Royer, R. A.; Burgos, W. D. The roles of natural organic matter in chemical and microbial reduction of ferric iron. Science of the Total Environment 2003, 307, 167-178; DOI 10.1016/s0048-9697(02)00538-7.

20. Rosario-Ortiz, F. L.; Korak, J. A. Oversimplification of dissolved organic matter fluorescence analysis: Potential pitfalls of current methods. Environ. Sci. Technol. 2017, 51, 759-761; DOI 10.1021/acs.est.6b06133.

21. Kaiser, K.; Kalbitz, K. Cycling downwards - dissolved organic matter in soils. Soil Biol. Biochem. 2012, 52, 29-32; DOI 10.1016/j.soilbio.2012.04.002.

22. Gauthier, T. D.; Shane, E. C.; Guerin, W. F.; Seitz, W. R.; Grant, C. L. Fluorescence quenching method for determining equilibrium constants for polycyclic aromatic hydrocarbons binding to dissolved humic materials. Environ. Sci. Technol. 1986, 20, 1162-1166; DOI 10.1021/es00153a012.

23. Lawaetz, A. J.; Stedmon, C. A. Fluorescence intensity calibration using the Raman scatter peak of water. Appl. Spectrosc. 2009, 63, 936940; DOI 10.1366/000370209788964548.

24. Bro, R. PARAFAC. Tutorial and applications. Chemometr. Intell. Lab. 1997, 38, 149-171; DOI 10.1016/s0169-7439(97)00032-4.

25. Bro, R.; DeJong, S. A fast non-negativity-constrained least squares algorithm. J. Chemometr. 1997, 11, 393-401; DOI 10.1002/(sici)1099128x(199709/10)11:5<393::aid-cem483>3.0.co;2-1.

26. Lovley, D. R.; Phillips, E. J. P. Availability of ferric iron for microbial reduction in bottom sediments of the freshwater tidal Potomac river. Appl. Environ. Microbiol. 1986, 52, 751-757; DOI 10.1128/AEM.52.4.751-757.1986. 
27. Nelson, P. N.; Baldock, J. A. Estimating the molecular composition of a diverse range of natural organic materials from solid-state ${ }^{13} \mathrm{C}$ NMR and elemental analyses. Biogeochemistry 2005, 72, 1-34; DOI 10.1007/s10533-004-0076-3.

28. Abdulla, H. A. N.; Minor, E. C.; Dias, R. F.; Hatcher, P. G. Changes in the compound classes of dissolved organic matter along an estuarine transect: A study using FTIR and C-13 NMR. Geochim. Cosmochim. Acta 2010, 74, 3815-3838; DOI 10.1016/j.gca.2010.04.006.

29. Knicker, H.; Ludemann, H. D.; Haider, K. Incorporation studies of $\mathrm{NH}_{4}{ }^{+}$during incubation of organic residues by ${ }^{15} \mathrm{~N}-\mathrm{CPMAS}-\mathrm{NMR}-$ spectroscopy. Europ. J. Soil Sci. 1997, 48, 431-441; DOI 10.1111/j.1365-2389.1997.tb00209.x.

30. Kalinowski, H. O.; Berger, S.; Braun, S. ${ }^{13}$ C NMR Spektroskopie. Thieme: Stuttgart, Germany, 1984.

31. Chen, J.; Gu, B. H.; LeBoeuf, E. J.; Pan, H. J.; Dai, S. Spectroscopic characterization of the structural and functional properties of natural organic matter fractions. Chemosphere 2002, 48, 59-68; DOI 10.1016/s0045-6535(02)00041-3.

32. Baldock, J. A.; Masiello, C. A.; Gelinas, Y.; Hedges, J. I. Cycling and composition of organic matter in terrestrial and marine ecosystems. Mar. Chem. 2004, 92, 39-64; DOI 10.1016/j.marchem.2004.06.016.

33. Wolf, M.; Kappler, A.; Jiang, J.; Meckenstock, R. U. Effects of humic substances and quinones at low concentrations on ferrihydrite reduction by Geobacter metallireducens. Environ. Sci. Technol. 2009, 43, 5679-5685; DOI 10.1021/es803647r.

34. Mazzetti, L.; Thistlethwaite, P. J. Raman spectra and thermal transformations of ferrihydrite and schwertmannite. J. Raman Spectrosc. 2002, 33, 104-111; DOI 10.1002/jrs.830.

35. Socrates, G. Infrared and Raman characteristic group frequencies: Tables and charts. 3rd ed.; John Wiley \& Sons Ltd: Chichester, U.K., 2001.

36. Eusterhues, K.; Rennert, T.; Knicker, H.; Kögel-Knabner, I.; Totsche, K. U.; Schwertmann, U. Fractionation of organic matter due to reaction with ferrihydrite: Coprecipitation versus adsorption. Environ. Sci. Technol. 2011, 45, 527-533; DOI 10.1021/es1023898.

37. Eusterhues, K.; Hädrich, A.; Neidhardt, J.; Küsel, K.; Keller, T. F.; Jandt, K. D.; Totsche, K. U. Reduction of ferrihydrite with adsorbed and coprecipitated organic matter: microbial reduction by Geobacter bremensis vs. abiotic reduction by Na-dithionite. Biogeosciences 2014, 11, 4953-4966; DOI 10.5194/bg-11-4953-2014.

38. Cooper, R. E.; Eusterhues, K.; Wegner, C. E.; Totsche, K. U.; Küsel, K. Ferrihydrite-associated organic matter (OM) stimulates reduction by Shewanella oneidensis MR-1 and a complex microbial consortia. Biogeosciences 2017, 14, 5171-5188; DOI 10.5194/bg-14-5171-2017.

39. Rancourt, D. G.; Ping, J. Y. Voigt-based methods for arbitrary-shape static hyperfine parameter distributions in Mössbauer spectroscopy. Nucl. Instrum. Meth. B 1991, 58, 85-97; DOI 10.1016/0168-583x(91)95681-3.

40. Filella, M.; Zhang, J. W.; Newman, M. E.; Buffle, J. Analytical applications of photon correlation spectroscopy for size distribution measurements of natural colloidal suspensions: Capabilities and limitations. Colloid Surf. A-Physicochem. Eng. Asp. 1997, 120, 27-46; DOI 10.1016/S0927-7757(96)03677-1. 